\title{
PROGRAMA DE LAQUEADURA RELATO DE EXPERIÊNCIA COM GRUPO MULTIPROFISSIONAL
}

\author{
Maria Inês Monteiro Cocco* \\ Maria José A. Frolini Palu** \\ Elaine Regina S. da Silva***
}

\begin{abstract}
RESUMO - Relato de experiência com grupo multiprofissional. É relatada a experiência da atuação de um grupo multiprofissional junto a clientes grávidas e não grávidas, que procuram método de contracepção definitivo, visando a conscientização delas enquanto mulheres. São discutidos os métodos contraceptivos, aspectos da sexualidade, o papel e o direito da mulher, inserida num contexto social amplo.
\end{abstract}

\begin{abstract}
Multiprofissional experience data. The experience of a multiprofissional group is informed directed to pregnant and no pregnant woman that look for definitive contraception as a maner of getting of their condicions as woman. Contraceptives metods are discussed, physiologics and sexologics aspects jointly with information about the surgery.
\end{abstract}

\section{INTRODUC̣ÃO}

Vários fatores englobam o planejamento familiar, interferindo e alterando sua evolução: a política, o setor econômico, o social, o moral e o religioso. 0 controle da explosão demográfica tornou-se uma polêmica discutida em todas as partes do mundo atualmente.

Falando-se em planejamento familiar e considerando a grande quantidade que temos de métodos contraceptivos alternativos, a laqueadura ainda é a primeira opção de escolha de muitas mulheres.

A grande maioria delas faz esta escolha principalmente pelo não conhecimento de outros métodos contraceptivos e também por achar que a cirurgia irá resolver todos os problemas de sua vida e, sobretudo, o relacionamento sexual com o parceiro. A aceitabilidade pode estar relacionada também com a maior segurança e facilidade da cirurgia devido às técnicas operatórias e anestésicas atualmente desenvolvidas.

No final da década de 70 teve início, no Hospital das Clínicas da UNICAMP, 0 atendimento individual a casais interessados na esterilização definitiva feminina. Era realizada uma entrevista com o casal, onde fazia-se uma abordagem geral sobre métodos contra- ceptivos, a cirurgia de laqueadura e as razões pela opção do método definitivo. A equipe que atendia a estes casais era composta por uma assistente social e uma enfermeira. Após a entrevista, uma equipe médica prédeterminada avaliava a situação de cada casal das fichas preenchidas e aprovava-se ou não a cirurgia. A assistente social comunicava então o resultado aos casais.

Visando dinamizar o atendimento aos casais, em março de 1986, tal esquema foi alterado.

Neste trabalho relatamos o atendimento que é prestado aos casais que comparecem ao nosso serviço em busca de esterilização definitiva, abordando as causas que levaram à escolha, suas queixas e insatisfações.

\section{REVISÃO BIBLIOGRÁFICA}

Segundo BELFORT, citado em SOUZA (1986) "Planejamento familiar é na definição dos peritos a utilização voluntária e consciente por parte do casal, do instrumento necessário à planificação do número de filhos e espassamento entre uma gestação e outra, mediante o uso de métodos anticoncepcionais disponíveis".

\footnotetext{
${ }^{*}$ Enfermeira Supervisora dos Ambulatórios do HC - UNICAMP, Mestranda em Educação - UNICAMP. Autora.

** Enfermeira Responsável pelo Ambulatório de Tocoginecologia do HC, UNICAMP.

*** Enfermeira Responsável pelo Ambulatório de Clínica Especializada do HC - UNICAMP
} 
Na série de textos básicos do BRASIL (1984), atribui ao planejamento familiar "o lugar adequado no contexto das ações da saúde, não devendo ser encarado como solução de problemas sociais e econõmicos e nem ignorado a sua inegável interface com o setor saúde".

Também COSTA NETO, citado em SOUZA (1986), relata que erı 1968 na cidade de Teerã, na CONFERÊNCIA INTERNACIONAL SOBRE DIREITOS HUMANOS, convocada pela Organização das Nações Unidas, delegados de 84 países (incluindo o Brasil) destacaram "que os casais têm o direito fundamental de decidirem livre e responsavelmente quanto ao número e espassamento dos seus filhos e o direito de obterem instrução e orientação adequada a respeito". E continua mencionando "por ocasião da Conferência Mundial de População de Bucareste em 1974, o Brasil declara sua aceitação formal ao planejamento familiar através da liberação de informações sobre $o$ assunto e a facilitação ao acesso de métodos necessários". E, ainda que cabe ao "Estado a responsabilidade de proporcionar informação e meios para que todos possam planejar suas famílias, of erecer serviços adequados e adotar medidas necessárias para a redução da mortalidade geral, especialmente a infantil".

Dentre as diretrizes gerais propostas pelo BRASIL (1984), destacamos a seguinte: "O conceito de integridade da assitência pressupõe uma prática educativa que permeia todas as ações desenvolvidas assegurando a apropriação pela clientela dos conhecimentos necesários a um maior controle sobre sua saúde".

ALVES (1986), relata que "o processo de conscientização em planejamento familiar mexe com o acervo de valores culturais de cada indivíduo, implicando em gradativa mudança de comportamento, ideais e atitudes".

Quanto aos conteúdos programáticos é enfatizado que "em todos os contatos da mulher com os serviços de saúde, serão dadas informações sobre o exercício da sexualidade, a fisiologia da reprodução, a regulação da fertilidade e os riscos do aborto provocado, prevenção de doenças sexualmente transmissíveis, do câncer cérvico-uterino e de mama, bem como a melhoria dos hábitos higiênicos e dietéticos. Para execuçâo dessa atividade informativa, os serviços podem optar por discussões individuais, em grupo ou outras formas mais compatíveis com sua estrutura organizacional'. (BRASIL, 1984).

Com relação à freqüência da esterilização feminina nos vários países, NORTMAN citado por PINOTTI et alii (1986), mostra os dados referentes ao início da década de 80 , segundo os quais "o maior número de esterilizações correspondiam à República Popular da China, Índia e Estados Unidos (40, 24, 13 milhões, respectivamente). Entre os países da América Latina, as taxas mais altas correspondem ao Panamá, El Salvador e Costa Rica, com taxas acima de $20 \%$ das mulhe- res em idade reprodutiva".

Quanto à satisfação ou não das mulheres após a cirurgia PINOTTI et alii (1986) em estudo realizado com 231 mulheres submetidas há pelo menos 3 anos de esterilização tubária verificaram:

- $72,7 \%$ delas estavam satisfeitas e repetiriam a intervenção;

- $13,8 \%$ estavam satisf eitas, embora com algum problema, e 27,3\% destas não repetiriam a intervenção;

- $1,7 \%$ estavam insatisfeitas; e

- $11,6 \%$ estavam arrependidas, e recomendavam evitar a esterilização tubária antes dos 25 anos, pois $50 \%$ delas estavam arrependidas de a ter feito".

THOMPSON et BARID (1968), citado em PINOTTI et alii (1986), " acharam que houve menos satisfação quando a laqueadura foi feita só por razões médicas, psiquiátricas ou obstétricas, já que $25 \%$ dessas mulheres queriam ter mais filhos". Continuando, cita que EMENS et OLIVE "estudaram 336 mulheres laqueadas e observaram que $15 \%$ estavam insatisf eitas, sendo que todas aquelas que tinham sido laqueadas por indicação médica durante a cesária estavam insatisfeitas".

BARROSO (1984), mostra que, embora haja numerosos abusos de esterilizações praticadas sem o consentimento consciente da mulher, é provável que grande parte das esterilizações tenham sido solicitadas pelas clientes, mas dentro de um conjunto de alternativas que elas são impotentes para alterar. Estas alternativas decorrem de determinantes sociais: posição desvantajosa da mulher na família e no mercado de trabalho, a cultura patriarcal, a política de mercantilização da saúde e a política demográfica.

\section{METODOLOGIA E COMENTÁRIOS}

As mulheres que procuram atendimento neste hospital para uma contracepção definitiva vêm encaminhadas dos Centros de Saúde de Campinas e região, e de vários setores do próprio hospital, mediante indicação médica ou por opção dela mesma.

É marcada uma reunião só com as mulheres, quando então é feita uma ação educativa, onde elas falam sobre suas histórias de vida, seu relacionamento familiar e sexual, dentro do seu contexto sócio-econõmico e cultural.

Relatam os métodos contraceptivos utilizados pelo casal até então, os problemas a eles relacionados, porque optaram pela laqueadura, e se foi decisão da mulher ou do casal. Essa reunião é realizada pela enfermeira e assistente social, contando com a retaguarda de psicóloca e médicos do Departamento de Tocoginecologia da UNICAMP. Durante a reunião a enfermeira faz uma explanação sobre o aparelho genital feminino, onde é debatido sobre o conhecimento a respeito do aparelho feminino e sua percepção corporal.

Em seguida, é explicado que o planejamento fami- 
liar é um direito básico, uma prática, e uma técnica do casal, para poderem decidir responsável e conscientemente sobre o número de filhos e o espaçamento entre eles. É orientado em relação aos métodos contraceptivos utilizados atualmente, mostrando-os ao grupo e explicando sobre suas indicações, contra-indicações e ef eitos colaterais. Por último, são abordados os aspectos referentes à laqueadura; como a cirurgia, a anestesia, o pós-operatório e é discutido com as participantes do grupo sobre suas dúvidas e o que já ouviram falar sobre $o$ assunto (frigidez, aumento ponderal, nova gravidez, alterações no ciclo menstrual).

No decorrer das reuniões notamos que as clientes estavam interessadas em discutir os aspectos sexuais do relacionamento do casal, que para algumas, aquela era a primeira oportunidade para falarem isso em grupo, e que era algo que ocorria com outras mulheres também. Quando indagadas sobre a sua percepção corporal, poucas tinham noções do aparelho genital feminino, exceto as que já tinham sido atendidas na UNICAMP, e em alguns centros de saúde.

Quanto à opção pela laqueadura, nem sempre esta decisão era do casal; muitas vezes era indicação médica, ou apenas a mulher é que decidiu não ter mais filhos. Outro aspecto a ser considerado é que algumas clientes queriam ter mais filhos, porém, a situação sócio-econômica não o permitia (dificuldade para conseguir emprego, creche, baixa renda familiar).

Com relação à estabilidade conjugal, nem todas as mulheres aceitavam a possibilidade de ter mais filhos num segundo ou terceiro matrimônio, já que não havia dado certo no primeiro; no outro, os parceiros deveriam aceitá-las como eram (no caso, não poderiam mais ter filhos).

Este estudo se baseou no trabalho que vem sendo realizado pelo grupo multiprofissional ligado ao ambulatório de tocoginecologia do Hospital das Clínicas da Universidade Estadual de Campinas, que atende a clientes que desejam um método contraceptivo definitivo.

Foi feita uma análise retrospectiva das anotações realizadas durante as reuniões, no período de março de 1986 a março de 1987 e foram selecionadas apenas aquelas que possuíam todos os seus dados preenchidos, mediante a ficha modelo, num total de 300 clientes.

Em relação ao estado gestacional das clientes que freqüentaram os grupos temos:

TABELA 1 - Distribuição das clientes segundo o estado gestacional - Campinas, 1987.

\begin{tabular}{lcc}
\hline Estado Gestacional & $\mathrm{n}$ & $\%$ \\
\hline gestante & 119 & 39,7 \\
não gestante & 181 & 60,3 \\
\hline Total & 300 & 100,0 \\
\hline
\end{tabular}

Encontramos, neste item, que a maior porcentagem $(60,3)$ de clientes atendidas é de não gestantes; embora grande parte $(39,7)$ seja de gestantes.

Quanto à faixa etária, encontramos:

TABELA 2 - Distribuição das clientes segundo a faixa etária - Campinas, 1987.

\begin{tabular}{|c|c|c|}
\hline Faixa Etária (anos) & $\mathrm{n}$ & $\%$ \\
\hline$<22$ & - & - \\
\hline $22-26$ & 24 & 8 \\
\hline $27-31$ & 102 & 34 \\
\hline $32-36$ & 99 & 33 \\
\hline $37-41$ & 45 & 15 \\
\hline $42-46$ & 28 & 9.3 \\
\hline$>46$ & 2 & 0,7 \\
\hline Total & 300 & 100,0 \\
\hline
\end{tabular}

A faixa etária das clientes que participaram das reuniões concentra-se nas idades de 27 a 31 anos (34\%) e de 32 a 36 anos (33\%); portanto, em plena fase produtiva de trabalho e no auge de sua reprodução.

Analisamos, a seguir, o número de filhos vivos que as clientes apresentam.

TABELA 3 - Distribuição das clientes segundo o número de filhos vivos - Campinas, 1987.

\begin{tabular}{lrr}
\hline \multicolumn{1}{r}{ Número de filhos } & $\mathrm{n}$ & $\%$ \\
\hline $1-3$ & 137 & 45,7 \\
$4-6$ & 130 & 43,3 \\
$7-9$ & 28 & 9,3 \\
$>10$ & 5 & 1,7 \\
\hline Total & 300 & 100 \\
\hline
\end{tabular}

Ressaltamos aqui o fato de $39,7 \%$ da população estudada ser gestante, o que elevará posteriormente ao término da gestação o número de filhos vivos.

Ao iniciarmos o grupo em sua nova fase, no início de 1986 , a população que procurava um método contraceptivo definitivo era composta por mulheres com elevado número de filhos, fato este que reverteu-se nos dias atuais, onde as com menos número de filhos é que estão buscando esta opção. Salientamos o fato de que este é o único hospital da cidade e da região, que realiza esta cirurgia de forma gratuita. 
Os métodos contraceptivos já utilizados pelo casal e também em uso são analisados na seguinte tabela:

TABELA 4 - Distribuição das clientes segundo o método contraceptivo já utilizado e em uso pelo casal, $\mathrm{Ca}$ pinas 1987.

\begin{tabular}{|c|c|c|}
\hline Método & $\mathrm{n}$ & $\%$ \\
\hline \multicolumn{3}{|c|}{ não pode utilizar nenhum } \\
\hline $\begin{array}{l}\text { método } \\
\text { nunca usou }\end{array}$ & $\begin{array}{r}2 \\
19\end{array}$ & $\begin{array}{l}0,8 \\
6,3\end{array}$ \\
\hline A.0. & 103 & 34,3 \\
\hline DIU & 16 & 5,3 \\
\hline A.I. & 19 & 6,3 \\
\hline coito interrompido & 9 & 3 \\
\hline $\mathrm{AO} / \mathrm{DIU}$ & 35 & 11,8 \\
\hline $\mathrm{AO} / \mathrm{DIU} / \mathrm{AI}$ & 8 & 2,8 \\
\hline $\mathrm{AO} / \mathrm{AI}$ & 36 & 12 \\
\hline CONDON & 5 & 1,8 \\
\hline DIU/AI & 10 & 3,3 \\
\hline Norplant $^{\circledR}$ e outros & 7 & 2,3 \\
\hline $\mathrm{AO} / \mathrm{AI} /$ outros & 4 & 1,3 \\
\hline AO/outros & 15 & 5 \\
\hline AI/outros & 8 & 2,7 \\
\hline A0/DIU/outros & 2 & 0,8 \\
\hline laqueadura & 1 & 0,3 \\
\hline outros & 1 & 0,3 \\
\hline Total & 300 & 100 \\
\hline
\end{tabular}

A.O. = anticoncepcional oral

DIU = dispositivo intra-uterino

A.I. = anticoncepcional injetável

Estes métodos relatados pelas clientes eram utilizados tanto espontaneamente como por orientação médica, mas nem sempre elas citaram todos os métodos que usavam. 0 método utilizado com maior freqüência $(34,3 \%)$ foi o Anticoncepcional Oral.

Em toda a população estudada, $6,3 \%$ nunca utilizou nenhum método contraceptivo; e $0,8 \%$ relatou não poder usar nenhum método.
Em relação à presença ou não de patologias, temos o seguinte:

TABELA 5 - Distribuição das clientes quanto à presença de patologias.

\begin{tabular}{lcc}
\hline Patologia & $\mathrm{n}$ & $\%$ \\
sim & 128 & 42,7 \\
não & 172 & 57,3 \\
\hline Total & 300 & 100,0 \\
\hline Tipo de Patologia & $\mathrm{n}$ & $\%$ \\
\hline hipertensão arterial & 32 & 25,4 \\
cônjuge com problemas & 13 & 10,3 \\
doenças cardíacas & 5 & 4 \\
problemas ginecológicos & 5 & 4 \\
câncer ginecológico & 5 & 4 \\
aparelho urinário & 8 & 6,3 \\
aparelho respiratório & 5 & 4 \\
doenças do colágeno & 3 & 2,4 \\
doenças hereditárias & 7 & 5,5 \\
aparelho gastro-intestinal & 3 & 2,4 \\
aparelho circulatório & 4 & 3,2 \\
incompatibilidade & & \\
sangüínea & 2 & 1,6 \\
epilepsia & 3 & 2,4 \\
aparelho locomotor & 4 & 3,2 \\
artrite & 2 & 1,6 \\
4. cesária & 7 & 5,5 \\
problemas psiquiátricos & 13 & 10,3 \\
não pode ter filhos & 4 & 3,2 \\
outros & 1 & 0,7 \\
\hline Total & 126 & 100,0 \\
\hline
\end{tabular}

Durante a reunião, algumas clientes relatavam terem sido encaminhadas devido apresentarem patologias que limitavam novas gestações; embora não fosse necessariamente indicação médica. Notava-se que algumas delas buscavam justificativas orgânicas pela opção da laqueadura.

\section{CONCLUSÕES}

Em vista do trabalho desenvolvido na realização de grupos com clientes que buscam a contracepção definitiva num atendimento multiprofissional conclui-se que:

- com a nova dinâmica proposta para o grupo, houve maior conscientização das clientes, pois algumas delas ao conhecerem outros métodos contraceptivos desistiram da laqueadura;

- a discussão em grupo do que é a laqueadura permite às clientes a oportunidade de repensar seu papel enquanto mulher;

- o trabalho em equipe multiprofissional permite abor- 
dar a saúde num contexto mais amplo para com as clientes e na sua própria atuação;

- os métodos contraceptivos devem ser amplamente divulgados, visto que muitas mulheres os desconhecem, possibilitando assim um maior espaçamento entre os filhos, ficando a laqueadura para uma opção mais tardia.

\section{RECOMENDAC̣ÕES}

Considerando-se o trabalho desenvolvido no Hospital das Clínicas da UNICAMP com Grupo Multiprofissional no atendimento a clientes que buscam laqueadura, recomenda-se que:

- o enfermeiro assuma o seu papel na equipe multiprofissional, atuando na área de educação e saúde;

- o planejamento familiar seja de fato da livre escolha do casal;

- 0 atendimento seja efetivo para todas as camadas sociais (e não enfatizando a não opção pela cirurgia apenas para as camadas de baixa renda e liberando para as mulheres que têm condições sócio-econômicas para pagarem a cirurgia);

- haja ampla informação sobre os métodos disponíveis e riscos; e que a laqueadura seja realmente a última opção como método contraceptivo.

\section{REFERÊNCIAS BIBLIOGRÁFICAS}

1. ALMEIDA, M.M.G. O Enfermeiro no planejamento familiar. Revista Brasileira de Enfermagem, Brasília, 38(3/4): 215-30, jul./dez. 1985.
2. ALVES, E.D. et alii. A atuação do enfermeiro na orientaçāo em planejamento familiar junto à comunidade. In: $\mathrm{CON}$ GRESSO BRASILEIRO DE ENFERMAGEM, 38. Rio de Janeiro, 20 a 24 de outubro de 1986 . mimeogr.

3. BARROSO, C. Esterilização feminina: liberdade e opressão. $R \boldsymbol{e}$ vista de Saúde Pública, 18(2): 170-80, abr. 1984.

4. BRASIL. Ministério da Saúde: Assistência integral à saúde da mulher: bases de ação programática. Brasília, Centro de Documentação, 1984.

5. CANESQUI, A.M. A implantação e expansão dos serviços e planejamento familiar: questões e controvérsias. Revista Paulista de Enf ermagem. São Paulo, 5(1): 26-30, jan/mar. 1985.

6. DI LASCIO, C.S. A saúde da mulher como prioridade nos programas de saúde. In: CONGRESSO BRASILEIRO DE ENFERMAGEM, 36. Belo Horizonte, 23 jul. a 3 ago. de 1984. Anais... Brasília, ABEn 1984. p. 85-116.

7. HERRMANN, J. et alii. Síndrome pós-laqueadura. Femina, Rio de Janeiro, 13: 845-49, set. 1985.

8. HOLTROP, H.R. et WAIFE, R.A. Técnicas de minilaparotomia. EUA, The Pathfinder Fund, 1979.

9. LIMA, H.A.M. Explosão populacional à luz da explosão nuclear. Femina. Rio de Janeiro 13(5): 450-68, maio 1985.

10. NAKAMURA, M.S. Planejamento familiar. (Xerocópia distribuída no curso de Planejamento Familiar), Chile, 1980.

11. PINOTTI, J.A. et alii. Identificação de fatores associados à insatisfação após esterilização cirúrgica. Revista Brasileira de Ginecologia e Obstetrícia, 9(4): 304-09, 1986.

12. PORTER, C.N. et alii. Anticoncepcionais orais: guia para pro gramas e clínicas. The Pathfinder Fund, 3. ed. EUA, 1981.

13. SCLIAR, M.J. Saúde e educação. Estratégias de mudanças. In: CONGRESSO BRASILEIRO DE ENFERMAGEM, 34, Porto Alegre, 24 a 29 de outubro de 1982. Anais... Brasília, ABEn, 1982, p.21-4.

14. SOUZA, C.P. de et alii. O papel do enf ermeiro no planejamento familiar. In: CONGRESSO BRASILEIRO DE ENFERMAGEM, 38, Rio de Janeiro, 20 a 24 de out. de 1986 mimeogr. 